\title{
ENERGY HARVESTING METHODS IN AVIATION
}

\author{
Martin SCHRÖTTER* and Róbert BRÉDA \\ Department of Avionics, Faculty of Aeronautics, Technical University of Kosice, 04001 Košice, \\ Slovakia \\ Peter KALAVSKÝ \\ Department of Fight Training, Faculty of Aeronautics, Technical University of Kosice, 04001 Košice, \\ Slovakia
}

\section{Olena KOZHOKHINA}

Department of Avionics, Faculty of Air Navigation, Electronics and Telecommunications, National Aviation University, 03058 Kyiv, Ukraine

*Corresponding author. E-mail: martin.schrotter@tuke.sk

\begin{abstract}
Each modern aircraft uses many sensors to sense different operating parameters. Sensed parameters are subsequently sent to the appropriate computer for processing. Because many sensors are often remotely located, they require long power and signal wires. Moreover, the routing of large number of wires complicates the design of the aircraft. This is an issue, especially in passages from pressurized to non-pressurized areas and near fuel tanks. For all these reasons, it is attractive to use sensors with their own power supply and wireless communication possibility. Today, most of remotely located sensors use electrochemical voltage sources, however they imply environmental and reliability issues. The solution is to use sensors that generate their own energy. This article points out the possibility of using on-board sensors with energy harvesting technology.
\end{abstract}

Keywords: energy harvesting; structural health monitoring; transducers; sensors

\section{INTRODUCTION}

Modern aircraft uses many different sensors that monitor operating parameters during the flight. The most common is monitoring of the airframe structure, engine conditions, vibration, outdoor and indoor temperature, and humidity [1]. All these sensors need electricity for their operation. The traditional way to supply electric power to sensors is realized by wires connected to the aircraft's electrical network. In the case of large aircraft, such as an Airbus A380, the total length of 98'000 wires can exceed $470 \mathrm{~km}$ with a weight of $5700 \mathrm{~kg}[2,3]$. Such a quantity of conductors presents, in addition to a weight handicap, routing problems in the airframe, because power and signal conductors must not be routed in the same harness. The second, currently widely used, method to power remotely located sensors is with primary or secondary cells. However, the sources of electrochemical energy have serious drawback - their properties depend on the operating conditions (temperature, pressure and humidity). Other disadvantages are short lifetime, limited power density, leakage problem and ecological burden associated with their recycling [4]. In general, primary cells must be replaced regularly. In case of secondary cells, they must be regularly recharged during the maintenance. Due to the disadvantages of electrochemical energy sources, sensors that are capable to obtain energy from the surrounding (waste) energies come to the fore. Such sensors are known as energy harvesting sensors. If they are additionally equipped with a wireless communication interface, then the use of power and data wires can be eliminated. This article presents viable energy harvesting methods that can be theoretically used in aviation. The article is structured as follows, Chapter 2 deals with the use of wireless sensors in aviation, Chapter 3 discusses the different methods of energy harvesting, and Conclusion summarizes up to date research on energy harvesting sensors suitable for aviation purposes. 


\section{THE USE OF WIRELESS SENSORS IN AVIATION}

The lifetime of aircraft is not limited by the number of its flight hours, but rather by the number of operating cycles - take-offs and landings. During these cycles, the aircraft structure is regularly stretched and compressed, resulting in the formation of micro cracks in its airframe. The condition of the airframe must therefore be monitored regularly. Inspections take place during scheduled aircraft maintenance [5]. However, this requires its grounding, which has adverse financial consequences for airlines. From this point of view, it is advantageous to use sensors that continuously monitor the structural condition of the airframe.

Sensors with wireless transmission, using energy harvesting technology, must include a sensor, power supply unit, power converter and management unit [6]. The operating mode of a sensor affects its power consumption. In sensing mode, it can only be $1 \mathrm{~mW}$ at $3.3 \mathrm{~V}$, however in transmission mode it can be several mA [7]. During the normal operation, the sensor unit is supplied only by energy harvester. In case the harvesting power decreases below the predetermined level, the sensor operation would be erroneous. For that reason, the additional power storage device, e.g., supercapacitor or secondary cell, must be used to compensate for power loss and fluctuations [6].

The power to weight ratio of such a solution determines the suitability of using sensors working based on energy harvesting in comparison with wired sensors. In Tab. 1, there are compared power densities of various energy harvesters suitable for aviation purposes. It is evident that the best energy harvesters in terms of power density are thermoelectric generators.

It is still an issue to use wireless communication in aviation. Metal structure of an aircraft poses a burden to wireless propagation so sensors must be placed only in areas with feasible signal propagation. For that reason, several access points will be needed to provide the wireless links between wireless sensors and an on-board data processing unit. Moreover, wireless communication is not convenient for sensors which generate a large amount of data and for sensors used in applications that demand very high reliability [8].

Table 1 Power densities of various energy harvesters [6]

\begin{tabular}{|c|c|}
\hline Energy harvesters & Power densities \\
\hline 3v-flexible Si solar cell 1000 1x (for inside applications) & $7 \mu \mathrm{W} / \mathrm{g}$ \\
\hline 3v-flexible Si solar cell $100001 \mathrm{x}$ (applications in shadow) & $280 \mu \mathrm{W} / \mathrm{g}$ \\
\hline Vibration generator VEH 360, $\mathrm{a}=0.24 \mathrm{~m} / \mathrm{s}^{2}$ & $2.78 \mu \mathrm{W} / \mathrm{g}$ \\
\hline Vibration generator VEH 360, $\mathrm{a}=0.98 \mathrm{~m} / \mathrm{s}^{2}$ & $37 \mu \mathrm{W} / \mathrm{g}$ \\
\hline Thermoelectric generator, $\Delta \mathrm{T}=10 \mathrm{~K}$ & $8 \mathrm{~mW} / \mathrm{g}$ \\
\hline Thermoelectric generator, $\Delta \mathrm{T}=40 \mathrm{~K}$ & $131 \mathrm{~mW} / \mathrm{g}$ \\
\hline
\end{tabular}

\section{TECHNOLOGIES IN ENERGY HARVESTING}

Loss of energy is inherent in each technical device during its operation, as no process is $100 \%$ efficient. An example is an internal combustion engine which efficiency does not exceed 50\% [9], the remaining energy is converted into "loss" heat and vibration. Another example is the operation of electrical machines - motors, generators, and converters, which efficiency is usually up to $95 \%$ $[10,11]$. In the case of generators of more electrified aircraft (MEA), which power can be up to 250 $\mathrm{kVA}$, these losses represent up to $12.5 \mathrm{kVA}$. The Boeing 787 uses 4 such generators. Another example is the vibration of airframe parts, which are caused by air flow or by engines and propellers operation. By applying suitable converters, it is possible to use this energy to supply small loads, such as sensors. 


\subsection{Photovoltaic effect}

The photovoltaic effect is the generation of electrical energy (voltage) in a material upon exposure to light. A device that converts solar energy into electricity is called a photovoltaic solar cell. When a photon with a suitable energy hits a solar cell, it excites the electron to a higher energy level, thereby passing into the conductive layer of the solar cell (Fig. 1). The single junction silicon solar cell can produce up to $0.6 \mathrm{~V}[12]$.

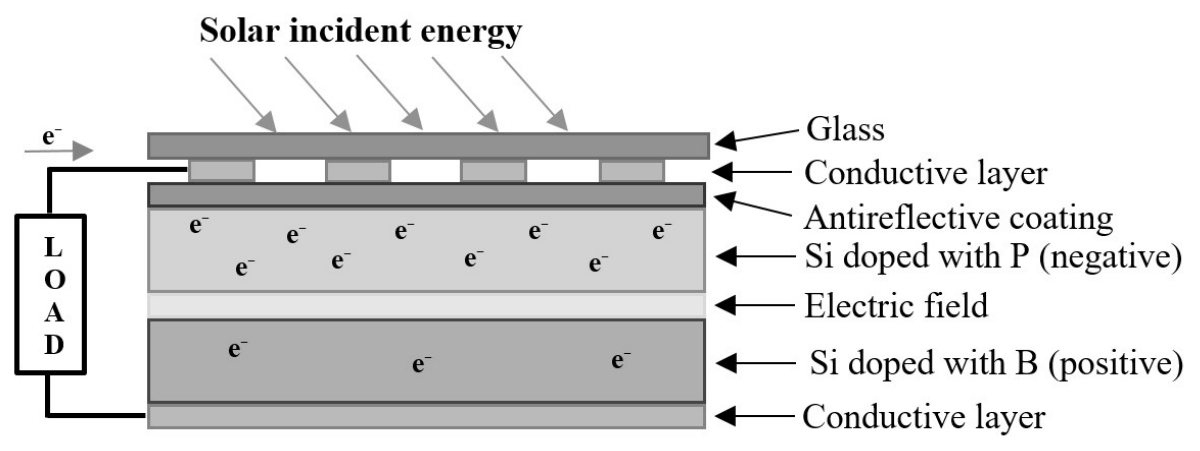

Figure 1 The principle of photovoltaic solar cell

Due to the power of the incident solar energy, which is approximately $1000 \mathrm{~W} / \mathrm{m}^{2}[13,14]$, it can be used in the case of a solar cell with good efficiency and power density, not only to power small sensors, but also to power larger appliances. The conversion efficiency of incident light into the electrical power is expressed by equation (1).

$$
\eta=\frac{V_{O C} \cdot J_{S C} \cdot F F}{P_{\text {in }}}
$$

where: $\eta$ is a power conversion efficiency, $V_{o c}$ is open-circuit voltage of a cell, $\mathrm{J}_{\mathrm{sc}}$ is short-circuit current, $\mathrm{FF}$ is a fill-factor and $\mathrm{P}_{\text {in }}$ is incident light power.

In 1980, the world's first piloted, solar-powered flight was realized with the aircraft Gossamer Penguin [15]. In 2018, a flight in the stratosphere took place with the Airbus Zephyr 8. This aircraft used gallium arsenide-based solar cells that during the flight recharged lithium-ion batteries with specific energy $435 \mathrm{Wh} / \mathrm{kg}$ [16]. In 2016, the first manned solar-powered flight around the world took place, with the Solar Impulse 2 aircraft, which used 17248 photo voltaic solar cells with an output of $66 \mathrm{~kW}$ and recharged 4 lithium-ion batteries during the flight [17]. The efficiency of current silicone solar cells is around $30 \%$, and gallium arsenide cells is around $40 \%$ [18].

\subsection{Thermoelectric effect}

The low-grade thermal energy harvesting technologies are based upon the thermoelectric, pyroelectric, thermomagnetic, and thermoelastic effect [19]. A thermoelectric effect is the generation of electrical energy based on a temperature gradient in materials that exhibits thermoelectric properties. In general, the thermoelectric effect is the resultant of Seebeck, Peltier and Thompson effects. A device working on Seebeck effect, which converts a thermal gradient into electrical energy, is called a thermoelectric generator [20].

During the Seebeck effect, DC voltage is formed when two ends of conductors made of different metals are connected. This effect is amplified if both ends have different temperatures. The induced voltage is directly proportional to the difference in their temperatures (Fig. 2). This can be mathematically expressed by Equation (2).

Thermoelectric generators have low energy conversion efficiency, only $1-10 \%$. On the other hand, they are self-sustainable which makes them suitable for providing power in remote areas. 
Thermoelectric generator of size $3 \mathrm{~cm} \times 3 \mathrm{~cm}$ can produce $4 \mathrm{~W}$ of electrical power across temperature difference of $180^{\circ} \mathrm{C}$ [21]. However, such a temperature difference at a short length is not common for most systems, so in practice power output of TEG is much lower.

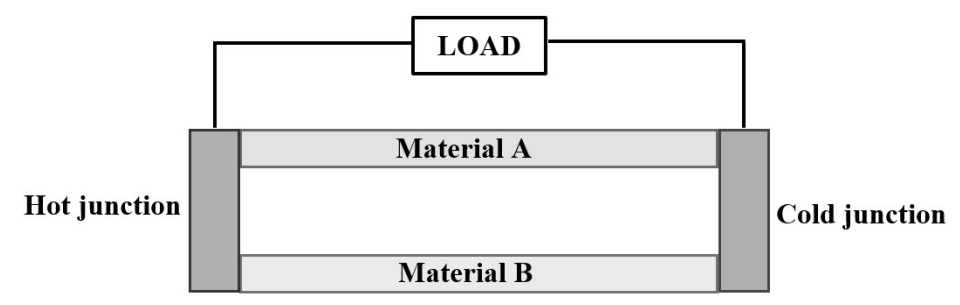

Figure 2 The principle of Seebeck effect

$$
V_{\text {out }}=\alpha_{A B} \times \Delta T
$$

where: $V_{\text {out }}$ is generated voltage, delta $T$ is temperature difference between hot and cold junction and $\alpha_{A B}$ is Seebeck coefficient for materials A and B of the thermocouple.

Temperature difference occurring in different structures during the flight can reach up to $40{ }^{\circ} \mathrm{C}$ in civil aircraft (Fig. 3). Because the size of TEG is usually very small, for effective power conversion, thermal gradient must be high. However, the high operating temperature of the devices is a problem with the application of a thermoelectric generators. In this case, the thermoelectric generator cannot be attached directly to the device, but a protective film must be inserted in-between, which artificially lowers the temperature on the inlet side of the generator to an acceptable value.

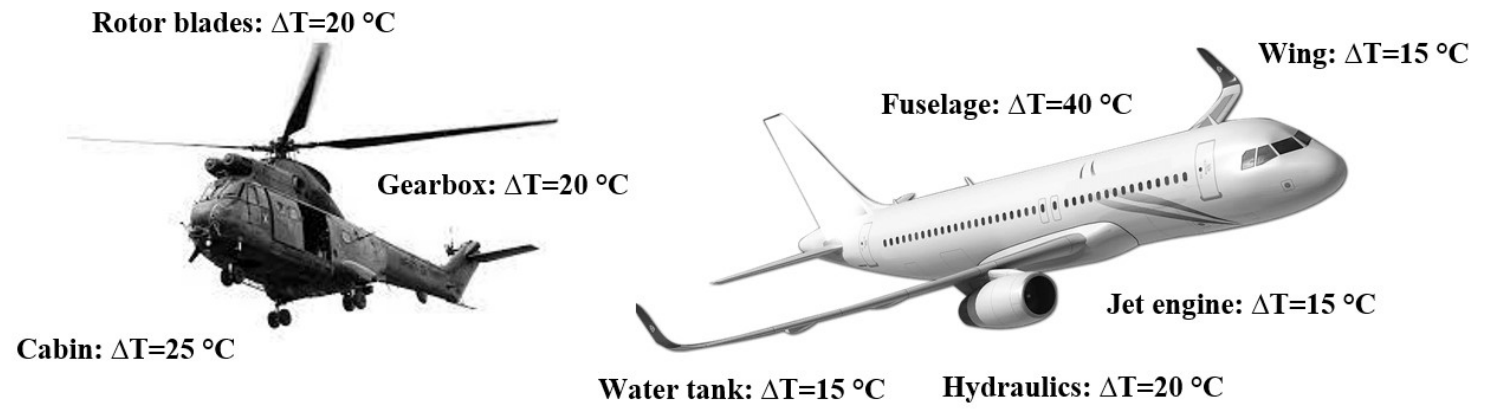

Figure 3 The typical temperature difference in selected locations of aircraft

\subsection{Pyroelectric effect}

The pyroelectric effect is the generation of electrical energy in the form of alternating current in materials during cyclic temperature change. The pyroelectric effect occurs in materials with internal electrical polarization, for which with increasing material temperature decreases electrical polarization and vice versa (Fig. 4). However, pyroelectric generators have a low efficiency, around $0.5 \%$, due to the limited temperature change frequency. This is limited to about $1 \mathrm{~Hz}$, due to the thermal conductivity between the thermal medium and pyroelectric generator [22]. These generators must be excellent thermal conductors with a low thermal mass. The efficiency of pyroelectric generator can be expressed by Equation (3):

$$
\eta=\frac{W_{E}-W_{P}}{C_{V} \Delta T+Q_{\text {int }}+Q_{\text {leak }}}
$$

where: $W_{E}$ is the generated AC power, $W_{P}$ is the power lost during cyclic temperature change, $C_{v}$ is the heat capacity of the pyroelectric generator material, $Q_{i n t}$ are the intrinsic heat losses during the thermal cycle and $Q_{\text {leak }}$ is the heat leakage between the hot and cold source. 

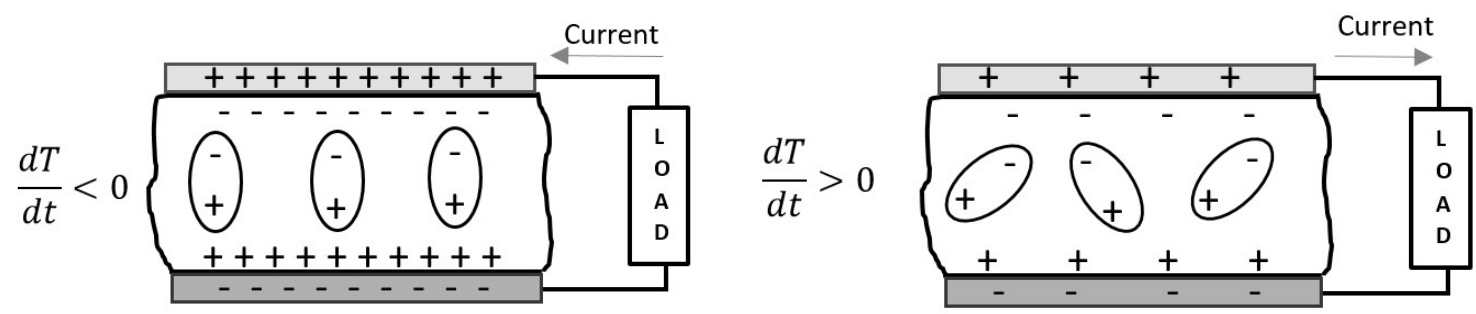

Figure 4 The principle of pyroelectric effect

\subsection{Piezoelectric effect}

Piezoelectric effect is the property of certain crystals to generate voltage in response to applied mechanical stress (Fig. 5). Most piezoelectric harvesters utilize the resonance of a cantilever beam. A cantilever beam, from a mechanical point of view, is equivalent to a vibrating lumped spring-mass system. The equation of motion of a lumped spring-mass system can be written as

$$
m \cdot \frac{d^{2} z(t)}{d t^{2}}+b \cdot \frac{d z(t)}{d t}+k \cdot z(t)=-m \cdot \frac{d^{2} y(t)}{d t^{2}}
$$

where: $\mathrm{m}$ - mass of a system, $\mathrm{k}$ - system stiffness, $\mathrm{b}$ - damping coefficient, $\mathrm{z}(\mathrm{t})$ - displacement as a function of time and $y(t)-$ initial impulse to the system.

Depending upon the frequency and amplitude of the mechanical stress, it is possible to design the proper transducer. Frequencies produced by rotors and propellers of aircraft, can be determined very easily. The typical rotor speed and blade passage frequency is in the range $10 \mathrm{~Hz}-80 \mathrm{~Hz}$ and the frequency produced by the jet engine is in the range $20 \mathrm{~Hz}-500 \mathrm{~Hz}$ [23].
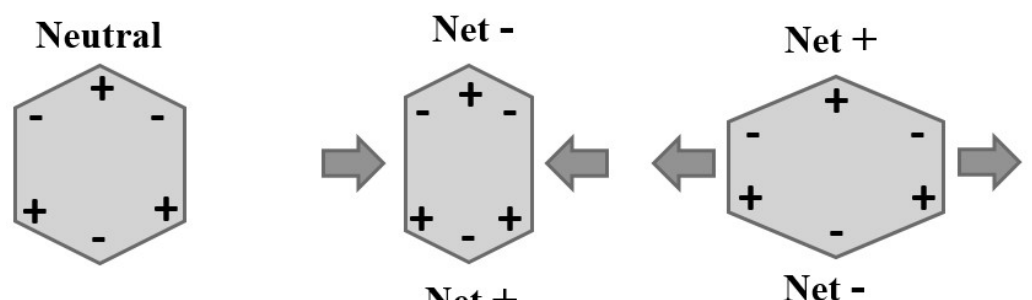

Net -

Figure 5 The principle of piezoelectric effect

\section{CONCLUSION}

Although the use of sensors based on energy harvesting does not bring a considerable weight reduction, it contributes to increased safety and to reduction of the environmental burden associated with the problematic recycling of batteries. At present, sensors based on energy harvesting technology are beginning to be used in aviation, especially in structural health monitoring and flight testing.

In [24], authors are investigating photovoltaic cells which supply pressure sensors during the aircraft testing. The system was operating well for irradiance of only $80 \mathrm{~W} / \mathrm{m}^{2}$. In [25], authors are investigating techniques for structural health monitoring with the use of energy harvesting wireless sensors. Authors conclude that proposed system can satisfy most structural monitoring requirements. In [26], authors are investigating the possibility of harvesting vibrational energy to enhance the flight endurance of small UAV and concluded the article that such a solution can be used soon to charge a small battery. In [27], authors propose device which can harvest energy from the dynamic deformation of an aircraft wing under gust loading. $100 \mu \mathrm{m}$-thick harvesters could generate energy exceeding 10 $\mathrm{J} / \mathrm{m}^{2}$. In [28], authors proposed an improved version of thermoelectric generator and power management unit with the conversion efficiency increased by $56 \%$. 
The best power density is provided by thermoelectric generators, however there are just few possible applications in aviation as they require high thermal gradient for effective operation. On the aircraft, TEGs can be placed near engines, APU, hydraulic lines and electrical generators. Solar cells provide very effective power conversion, however, they can operate only during the sunny days, so they require bulky power storage device which decreases it power density. Piezoelectric generators' efficiency is proportional to acceleration which limits their application in aviation. Rotor blades, engines' pylons and wing structure are all suitable for vibration harvesting but the incorporating piezoelectric elements into the structure cannot affect its mechanical properties.

Energy harvesting in aviation is promising technology, however, further improvements are required, especially on energy conversion efficiency.

\section{References}

[1] Gao, S., Dai, X., Hang, Y., Guo, Y., \& Ji, Q. Airborne wireless sensor networks for airplane monitoring system. Wireless Communications and Mobile Computing, 2018.

[2] Heinen, M. The A380 program. In: Global Investor Forum. EADS. 2006.

[3] Schwark, U., Pichavant, C. 1st ITU Inter-regional Workshop on WRC-15 Preparation Geneva, Switzerland, 4-5 December 2013, Available online (28.04.2021) at: $\mathrm{http} / / /$ ec.europa.eu/information_society/newsroom/cf/dae/document.cfm?doc_id=3916

[4] Sundriyal, P., \& Bhattacharya, S. Energy harvesting techniques for powering wireless sensor networks in aircraft applications: A review. Sensors for automotive and aerospace applications. 2019. $55-76$.

[5] Le, M. Q., \& et al. (Review on energy harvesting for structural health monitoring in aeronautical applications. Progress in Aerospace Sciences. 2015. 79, 147-157.

[6] Becker, T., Kluge, M., Schalk, J., Otterpohl, T., \& Hilleringmann, U. Power management for thermal energy harvesting in aircrafts. SENSORS, 2008 (pp. 681-684). IEEE.

[7] Arms, S. W., Townsend, C. P., Churchill, D. L., Galbreath, J. H., \& Mundell, S. W. Power management for energy harvesting wireless sensors. In Smart Structures and Materials 2005: Smart Electronics, MEMS, BioMEMS, and Nanotechnology (Vol. 5763, pp. 267-275). International Society for Optics and Photonics.

[8] Yang, T., Liu, J., \& Demirkiran, I. Are wireless sensors feasible for aircraft?. IEEE Potentials. 2009. 28(3), 36-39.

[9] Caton, J. A. Maximum efficiencies for internal combustion engines: Thermodynamic limitations. International Journal of Engine Research. 2018. 19(10), 1005-1023.

[10] Mecrow, B. C., \& Jack, A. G. Efficiency trends in electric machines and drives. Energy Policy. 2008. 36(12), 4336-4341.

[11] Trebuňa, F., Huňady, R., Bobovský, Z., \& Hagara, M. Results and experiences from the application of digital image correlation in operational modal analysis. Acta Polytechnica Hungarica, 2013. 10(5), 159-174.

[12] Meillaud, F., Shah, A., Droz, C., Vallat-Sauvain, E., \& Miazza, C. Efficiency limits for singlejunction and tandem solar cells. Solar energy materials and solar cells. 2006. 90(18-19), 2952-2959.

[13] Miková, L., Medvecká-Beňová, S., Kelemen, M., Trebuňa, F., \& Virgala, I. Application of shape memory alloy (SMA) as actuator. Metalurgija. 2015. 54(1), 169-172.

[14] Chegaar, M., Hamzaoui, A., Namoda, A., Petit, P., Aillerie, M., \& Herguth, A. Effect of illumination intensity on solar cells parameters. Energy Procedia, 2013. 36, 722-729.

[15] Safyanu, B. D., Abdullah, M. N., \& Omar, Z. Review of Power Device for Solar-Powered Aircraft Applications. Journal of Aerospace Technology and Management, 2019. 11.

[16] Airbus Zephyr Solar High Altitude Pseudo-Satellite Flies For Longer Than Any Other Aircraft During Its Successful Maiden Flight. Available (29.04.2021) at:

https://www.airbus.com/newsroom/press-releases/en/2018/08/Airbus-Zephyr-Solar-High-Altitude-

Pseudo-Satellite-flies-for-longer-than-any-other-aircraft.html

[17] Solar Impulse. Available (29.04.2021) at: https://aroundtheworld.solarimpulse.com/adventure 
[18] Kosten, E. D., Atwater, J. H., Parsons, J., Polman, A., \& Atwater, H. A. Highly efficient GaAs solar cells by limiting light emission angle. Light: Science \& Applications. 2013. 2(1), e45-e45.

[19] Kishore, R. A., Singh, D., Sriramdas, R., Garcia, A. J., Sanghadasa, M., \& Priya, S. Linear thermomagnetic energy harvester for low-grade thermal energy harvesting. Journal of Applied Physics. 2020. 127(4), 044501.

[20] Amatya, R., \& Ram, R. J. Solar thermoelectric generator for micropower applications. Journal of electronic materials, 2010. 39(9), 1735-1740.

[21] Kishore, R. A., \& Priya, S. A review on low-grade thermal energy harvesting: materials, methods and devices. Materials. 2018. 11(8), 1433.

[22] Hunter, S. R., Lavrik, N. V., Mostafa, S., Rajic, S., \& Datskos, P. G. Review of pyroelectric thermal energy harvesting and new MEMs-based resonant energy conversion techniques. In Energy Harvesting and Storage: Materials, Devices, and Applications III. 2012. (Vol. 8377, p. 83770D). International Society for Optics and Photonics.

[23] Kurtz, D. W., \& Marte, J. E. A review of aerodynamic noise from propellers, rotors, and lift fans. (1970). Technical Report 32-7462, N A T I O N A L AERONAUTICS AND SPACE A D M I N I S T R A T I O N

[24] Durand-Estèbe, P., Boitier, V., Berhouet, S., Labrousse, B., Bafleur, M., \& Dilhac, J. M. Energy harvesting for wireless in flight testing on A321 aircraft. In: More Electric Aircraft. (2015, February).

[25] Arms, S. W. \& et al. Energy harvesting wireless sensors and networked timing synchronization for aircraft structural health monitoring. In: 2009 1st International Conference on Wireless Communication, Vehicular Technology, Information Theory and Aerospace \& Electronic Systems Technology. 2009. (pp. 16-20). IEEE.

[26] Anton, S. R., \& Inman, D. J. Vibration energy harvesting for unmanned aerial vehicles. In: Active and Passive Smart Structures and Integrated Systems. 2008. (Vol. 6928, p. 692824).

[27] Pozzi, M., Guo, S., \& Zhu, M. Harvesting energy from the dynamic deformation of an aircraft wing under gust loading. In Health Monitoring of Structural and Biological Systems. 2012 (Vol. 8348, p. 834831). International Society for Optics and Photonics.

[28] Samson, D., Kluge, M., Becker, T., \& Schmid, U. Wireless sensor node powered by aircraft specific thermoelectric energy harvesting. Sensors and Actuators A: Physical. 2011. 172(1), 240-244.

Received 06, 2021, accepted 07, 2021

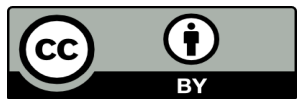

Article is licensed under a Creative Commons Attribution 4.0 International License 